\title{
A importância da língua de sinais para o desenvolvimento da pessoa surda: a noção de inclusão associada ao sentimento de pertencimento no espaço escolar
}

Patricia Velho Dall'Astra*

\section{Resumo}

Este artigo se propõe a expor conceitos relativos à deficiência auditiva, como a deficiência em si e a língua de sinais. Considerando a escola como um dos mais relevantes espaços de convivência das crianças (surdas e ouvintes) e o sentimento de pertencimento que as pessoas podem desenvolver concernente a esse espaço, será apresentada uma breve análise das três principais propostas da educação de surdos para, depois, estabelecer uma relação entre a língua de sinais e sua importância para o desenvolvimento da pessoa surda (especialmente nos casos de surdez pré-linguística), de modo a facilitar o processo de inclusão social da mesma. Conclui-se que a escola, por ser um espaço tanto de construção de conhecimento como de laços afetivos, é o lugar ideal para relacionar os conteúdos escolares com a cultura surda, além de incentivar ouvintes a aprenderem a língua de sinais desde cedo - e, através de uma comunicação eficiente entre pessoas com e sem deficiência, promover um ambiente cada vez mais verdadeiramente inclusivo.

Palavras-chave: Língua de sinais; Surdez; Educação.

* Designer de Interiores graduada pela Faculdade de Ciências Sociais de Florianópolis. Florianópolis, Santa Catarina, Brasil. 


\section{The importance of sign language for the development of the deaf person: the notion of inclusion associated to the sense of belonging in the school environment}

\section{Abstract}

This article aims to elucidate concepts related to the person with hearing disability, such as the disability itself and the sign language. Considering the school as one of the most important spaces for coexistence of children (deaf and hearing) and the sense of belonging that a person can develop in relation to the school, a brief analysis of the three main proposals of deaf education will be presented, to then establish a link between sign language and its importance for the development of the deaf person (especially in cases of pre-linguistic deafness), in order to facilitate their process of social inclusion. It is concluded that the school, being both a space of knowledge construction as of bonding, is the ideal place to relate school subjects to deaf culture, and encourage hearing people to learn sign language from an early age - and through efficient communication between people with and without disabilities, promote a truly inclusive environment.

Keywords: Sign language; Deafness; Education.

\section{Introdução}

A aquisição da linguagem é fator fundamental para o desenvolvimento humano, tanto para um ouvinte quanto para uma pessoa surda. Sobre o tema, o biólogo e neurologista Oliver Sacks (2010) levanta algumas questôes:

O que é necessário [...] para nos tornarmos seres humanos completos? O que denominamos nossa humanidade dependerá parcialmente da linguagem? O que acontece conosco se não aprendermos língua alguma? A linguagem desenvolve-se de um modo espontâneo e natural ou requer contato com outros seres humanos? (SACKS, 2010, p. 23).

Segundo Reily (2008), a criança aprende a falar naturalmente por encontrarse imersa num "mar de linguagem" (principalmente oral), onde sentidos são constituídos nas trocas entre interlocutores com níveis variados de competência linguística: outras crianças, adultos da família e adultos próximos ou mesmo desconhecidos. O domínio da língua se dá de forma contextualizada, em práticas significativas, e não por meio de exercícios artificiais.

Contudo, de acordo com Sacks (2010), a situação é muito diferente quando, já ao nascer, a audição está ausente ou quando ela é perdida na infância antes de a língua ser adquirida (estes casos são denominados surdez pré-linguística). Essas pessoas que nunca ouviram, que não têm lembranças, imagens ou associaçôes auditivas 
possíveis vivem num mundo de "absoluto e contínuo silêncio e ausência de som". Segundo o autor, pessoas com surdez pré-linguística, incapazes de ouvir seus pais ou outros parentes próximos, correm o risco de ficar seriamente atrasados, quando não permanentemente deficientes, na compreensão da língua, a menos que se tomem providências eficazes.

Ainda segundo Sacks (2010), ser deficiente na linguagem, para um ser humano, é uma das calamidades mais terríveis, porque é apenas por meio da língua que entramos plenamente em nosso estado e cultura humanos, que nos comunicamos livremente com nossos semelhantes, adquirimos e compartilhamos informaçóes. Embora o pensamento e a linguagem possuam origens biológicas separadas, e apesar de um ser humano não ter uma deficiência especificamente intelectual quando não adquire uma língua, este está gravemente restrito no alcance de seus pensamentos, confinado a um mundo imediato, pequeno. Além disso, está prejudicado também seu desenvolvimento emocional e social.

Para Joseph Church (1961, apud SACKS, 2010),

A língua transforma a experiência. [...] o aprendizado da língua transforma o indivíduo de tal modo que ele é capaz de fazer coisas novas para si mesmo ou coisas antigas de maneiras novas. A língua permite-nos lidar com coisas à distância, agir sobre elas sem manuseá-las fisicamente. Primeiro, podemos agir sobre outras pessoas, ou sobre objetos por meio de pessoas. [...] Segundo, podemos manipular símbolos de modos que seriam impossíveis com as coisas que eles representam e, assim, chegar a versóes inusitadas e criativas da realidade. [...] Podemos reorganizar verbalmente situaçóes que, em si mesmas, resistiriam à reorganização. [...] podemos isolar características que, na realidade, não podem ser isoladas. [...] podemos justapor objetos e eventos muito separados no tempo e no espaço. [...] podemos, se quisermos, simbolicamente virar do avesso o universo. (CHURCH, 1961, apud, SACKS, 2010, p. 45).

Segundo Vygotsky (1991), o desenvolvimento de funçóes psicológicas superiores não ocorre "naturalmente", de maneira automática. Necessita mediação, cultura, um instrumento cultural - e o mais importante destes é a língua. Mas, ainda segundo Vygotsky (1991), os instrumentos culturais e as línguas foram desenvolvidos para a pessoa sem deficiência, a pessoa que tem intactos todos os órgãos dos sentidos e suas funçóes biológicas. Enquanto que a pessoa com deficiência precisa de uma compensação: o uso de um instrumento cultural alternativo - que, no caso dos surdos, é a língua de sinais. Uma língua que faz uso das funçôes visuais (que ainda se encontram intactas, ou perto disso), que é o meio mais simples de lhes permitir o desenvolvimento pleno e o único que respeita sua diferença, sua singularidade. 


\section{Deficiência auditiva}

É nas pessoas com deficiência que podemos observar com mais nitidez as várias formas de ser como pessoa, pelo que são erroneamente reconhecidas como especiais ou extraordinárias, mas realizando apenas a condiçáo humana de estar no mundo de um modo diferente. (MARTINS, 2008, p, 30).

Os dados obtidos pelo IBGE, em 2010, revelaram que cerca de 46 milhóes de pessoas (quase $24 \%$ dos brasileiros) possuíam, naquele ano, pelo menos uma das deficiências investigadas (motora, visual, auditiva e intelectual). Deste percentual, cerca de 9,7 milhóes de pessoas declararam ter deficiência auditiva em algum grau.

O Decreto Federal 5626/2005 define tecnicamente a deficiência auditiva como "a perda parcial ou total bilateral, de quarenta e um decibéis $(\mathrm{dB})$ ou mais, aferida por audiograma nas frequências de $500 \mathrm{~Hz}, 1.000 \mathrm{~Hz}, 2.000 \mathrm{~Hz}$ e 3.000 $\mathrm{Hz}$ ". E o mesmo Decreto considera pessoa surda "aquela que, por ter perda auditiva, compreende e interage com o mundo por meio de experiências visuais, manifestando sua cultura principalmente pelo uso da Língua Brasileira de Sinais - Libras" (BRASIL, 2005).

Com relação a dizer "pessoa surda", "surdos" ou "pessoa com deficiência auditiva", geralmente, pessoas com surdez leve, moderada ou acentuada, referem-se a si mesmas como tendo uma deficiência auditiva; enquanto que as que têm surdez severa ou profunda se autodenominam surdas. Em um contexto formal, para questóes estatísticas, deve-se denominar "pessoa com deficiência auditiva", quando se referir ao grupo como um todo, seja qual for o grau da perda auditiva, e independente de características culturais específicas (SASSAKI, 2002).

Sob outro enfoque, Rodrigues (2008) diz que, para a comunidade surda, o deficiente auditivo é aquele que não participa de Associaçóes e não sabe Libras, a língua de sinais. O surdo é o alfabetizado e tem a Libras (Língua Brasileira de Sinais ${ }^{1}$ - no caso dos surdos brasileiros) como sua língua materna.

Quanto a características culturais, estas variam até mesmo dentro de grupos de pessoas com a mesma deficiência. Por exemplo, há os surdos oralizados e os não oralizados, que, geralmente, apresentam raízes distintas de concepção de mundo. De forma simplificada, surdos oralizados são aqueles que privilegiam a habilidade da fala e eficácia em leitura labial (ou então conseguem ouvir através de aparelhos auditivos ou implante coclear), aproximando-se mais da "Cultura Ouvinte". Os não oralizados não se comunicam através da fala, e sim da língua de sinais - a sua manifestação maior de "Cultura Surda". É importante mencionar, também, a existência dos surdos bilíngues bimodais, que têm a habilidade de se comunicar tanto pela língua de sinais como pela falada (MELLO, 2001).

No Brasil, a língua de sinais utilizada pela comunidade surda foi oficializada por lei em 2002, a fim de que os surdos brasileiros possam adquiri-la como língua materna, fazendo parte de sua identidade, auxiliando, também, na sua educação e sociabilidade. 


\section{Libras - Língua de Sinais Brasileira}

A Língua de Sinais Brasileira (Libras) é reconhecida como língua oficial de uso da comunidade surda brasileira e garantida em ambiente escolar nacional, conforme a Lei 9394/1996:

Será garantida às pessoas surdas, em todas as etapas e modalidades da educaçáo básica, nas redes públicas e privadas de ensino, a oferta da Língua Brasileira de Sinais - Libras, condição de língua nativa das pessoas surdas. (BRASIL, 1996).

Também garantida pela Lei 10.436/2002 como língua oficial de uso da comunidade surda, a Libras é a:

"forma de comunicação e expressão, em que o sistema linguístico de natureza visual-motora, com estrutura gramatical própria, constitui um sistema linguístico de transmissão de ideias e fatos, oriundos de comunidades de pessoas surdas do Brasil”. (BRASIL, 2002).

Para esclarecer a dúvida entre os termos "língua" e "linguagem", Capovilla (2001, apud SASSAKI, 2005) coloca que:

Lingua define um povo. Linguagem, um indivíduo. Assim, do mesmo modo como o povo brasileiro é definido por uma língua ou idioma em comum, o Português (que o distingue dos povos de todos os países com os quais faz fronteira), a comunidade surda brasileira é definida por uma língua em comum, a Língua de Sinais Brasileira. (CAPOVILLA, 2001, apud, SASSAKI, 2002).

É importante ressaltar, também, que a grafia certa é Libras e que, de acordo com Capovilla (2001, apud SASSAKI, 2005), o significado exato dessa sigla é Língua de Sinais Brasileira, ao invés de Língua Brasileira de Sinais, uma vez que não há uma Língua Brasileira (embora em documentos como a Lei 10.436/2002 e o Decreto Federal 5626/2005 esteja escrito da segunda forma). O termo "língua de sinais" constitui uma unidade vocabular, que funciona como se as três palavras fossem uma só, e que se refere a uma modalidade linguística visual-espacial e não oral-auditiva.

Ainda segundo Capovilla \& Raphael (2001) e Sassaki (2005), deve-se também ressaltar que a Libras é uma língua viva, cuja quantidade de sinais está em aberto, podendo ser acrescentados novos sinais com o passar do tempo. Portanto, devemos adjetivar cada "língua de sinais" que existe no mundo, como a Língua de Sinais Americana, a Língua de Sinais Francesa, a Língua de Sinais Mexicana, etc.

Como exposto anteriormente, Libras, independente do significado de sua sigla, está assegurada em ambiente escolar brasileiro. Todavia, náo basta regulamentar legalmente a inserçáo e uso desta língua; é necessário que, no ambiente escolar dedicado ao ensino do surdo, haja fluência em Libras por parte das pessoas que convivem ali. 


\section{O espaço escolar como ambiente social e o aprendizado da Libras}

Os espaços de vivência (como a casa, a escola e o bairro) representam uma experiência decisiva na aprendizagem e na formação das primeiras estruturas cognitivas; e, em sua materialidade, propiciam experiências espaciais que são fatores determinantes no desenvolvimento sensorial, motor e cognitivo. Além disso, esses espaços têm um sistema de valores implícitos que poderão contribuir, ou não, para que o espaço transforme-se em lugar, propiciando laços afetivos, sentimento de identidade e de pertencimento (PIAGET, 1970, apud RIBEIRO, 2004).

A sensação de pertencimento pode ser definida como um sentimento do indivíduo como pertencente a um determinado lugar, e que, este também lhe pertence. Assim, o indivíduo acredita que pode interferir no ambiente e que, acima de tudo, vale a pena interferir na rotina e nos rumos desse lugar (AMARAL, 2006).

Os laços afetivos, os sentimentos de identidade e de pertencimento são essenciais para o desenvolvimento da criança (seja ela surda ou ouvinte) e precisam da linguagem, a fim de que ela se comunique com outras pessoas e de fato pertença àquele espaço. Entretanto, o atraso que, em geral, acontece na aquisição da linguagem da criança surda causa, também, atraso na sua aprendizagem, no seu desenvolvimento e capacidade de interação social.

Bueno (2001) coloca que:

Os processos de urbanização parecem ter confinado à escola, cada
vez mais, a função de formação dos sujeitos, o que a transformou
em espaço social privilegiado de convivência e em ponto de re-
ferência fundamental para a constituiçáo das identidades de seus
alunos [...] em razão da transformação/restrição do espaço urbano,
se constituindo no local privilegiado de convivência de crianças
e jovens. [...] nas regiōes metropolitanas densamente povoadas, a
escola se constitui, hoje, no único espaço social de convivência de
crianças desde os seis/sete anos de idade. (BUENO, 2001, p. 105).

A partir das referências acima, pode-se constatar que a escola é um dos mais importantes espaços de convivência social da criança, e que a comunicação usada na escola deve contemplar as necessidades linguísticas de todos que ali permanecem. No caso das crianças surdas, é imprescindível que se faça uso da língua de sinais, uma vez que esta não é meramente uma alternativa à comunicação do surdo, e sim a língua oficial dessa comunidade.

Sendo assim, é muito importante que os educadores e demais funcionários das instituiçôes educacionais estejam cada vez mais capacitados a comunicar-se em Libras com fluência e constância. Conforme aponta Smith (2008), mesmo com um intérprete, a sala de aula do ensino regular pode ser um ambiente restritivo e causar isolamento se o aluno náo conseguir se comunicar e até participar de atividades extracurriculares com os colegas e os funcionários da escola. 
Amaral (1994) reflete sobre a situação de desvantagem, alegando que esta só acontece em situaçôes comparativas; ou seja, a desvantagem não ocorre necessariamente pela diferença (deficiência) em si, mas pela leitura social que é feita dessa diferença, dependendo das significaçôes afetivas, emocionais, intelectuais e sociais que o grupo atribui a determinadas características.

De acordo com Goldfeld (2002), a falta de exposição frequente à língua reduz muito a qualidade e a quantidade de informaçóes e assuntos abordados, se comparadas ao que os indivíduos ouvintes recebem e trocam. Nessas condiçóes, os surdos não são capazes de expressar e compreender assuntos além do "aqui e agora", não tendo dominado totalmente a funçáo planejadora da linguagem. Logo, fica evidente uma situação de desvantagem da criança surda em relação às crianças ouvintes.

$\mathrm{Na}$ tentativa de minimizar essa situação, a Prefeitura do Município de São Paulo, através do Decreto Municipal 52.785/2011, criou as Escolas Municipais de Educação Bilíngue para Surdos (EMEBS) e prevê que essas escolas promovam atividades de formação continuada em Libras para todos os funcionários (da equipe docente, equipe gestora e equipe de apoio) da unidade educacional (SÃO PAULO, 2011).

No entanto, Reily (2008) alerta que deve haver investimento e comprometimento na apropriação da língua de sinais dessas equipes, ao invés do aprendizado de alguns sinais apenas. Mesmo que seja de grande utilidade saber "alguns sinais" e ser capaz de contextualizar assuntos e acontecimentos aos surdos, assim como esclarecer e dar instruçóes durante o percurso escolar, isso não é satisfatório.

Para que o ambiente escolar seja eficiente no que tange à educação dos surdos e à capacitação da equipe de professores e funcionários, facilitando o desenvolvimento da convivência social e do sentimento de pertencimento, surgem algumas metodologias específicas para o ensino de surdos.

\section{Educação de Surdos: principais propostas e caminhos para a inclusão}

Os pressupostos básicos para metodologias da educaçáo de surdos estáo divididos em três principais correntes: o Oralismo, a Comunicaçáo Total e o Bilinguismo (DORZIAT, 1997).

\section{a. Oralismo}

Nessa proposta, acredita-se que a língua oral é a única forma desejável e efetiva de comunicação do surdo (OLIVEIRA, 2002).

Como explica Dorziat (1997), são utilizadas técnicas específicas para desenvolvê-la, como o treinamento auditivo (estimulaçáo auditiva para reconhecimento e discriminação de ruídos, sons ambientais e sons da fala); o desenvolvimento da fala (exercícios para mobilidade e tonicidade dos órgáos como lábio, mandíbula, língua, etc., e exercícios de respiraçáo e relaxamento); e a leitura labial (treino para identificação da palavra falada através da decodificação dos movimentos orais do emissor). 
Também, nesse método, indica-se a utilização de prótese individual, para amplificação dos sons, admitindo que existe resíduo auditivo mesmo em casos de surdez profunda - e, talvez, desconsiderando o fato de o uso de prótese demandar adaptação por parte do indivíduo, o que pode levar anos de terapia com fonoaudiólogos e psicoterapeutas.

Apesar de Vygotsky (1982, apud DORZIAT, 1997) criticar os métodos de desenvolvimento da fala para surdos, caracterizando-os como mecânicos, artificiais e penosos para a criança, em um primeiro momento, defende a importância da fala para o desenvolvimento do ser humano e, para tanto, admite ser a oralizaçáo a medida mais adequada para o ensino dos surdos. Náo obstante, o autor admitia também o uso de mímica (que náo é língua de sinais) fora de sala de aula.

Somente depois, Vygotsky (1991) muda sua postura, ao afirmar que a linguagem não depende da natureza do material que utiliza, pois o que realmente importa é o uso funcional de signos, sejam de quaisquer tipos, desde que possam exercer papel correspondente ao da fala. Essa visão surgiu entre os anos 1920 e 1930, mas somente a partir da década de 1960 é que os estudos sobre língua de sinais atribuíram-lhe o estatuto de língua.

Enquanto isso, alguns oralistas, que obtinham resultados negativos ou incompreendidos a partir de sua metodologia, tentavam se justificar, como comentam Freeman, Carbin \& Boese (1999):

Em vez de questionar a sabedoria de sua abordagem restritiva, os oralistas argumentam que os resultados de um treinamento oral, reconhecidamente pobres, originam-se do fato de náo se ter feito um diagnóstico o quanto antes, de não haver iniciado a amplificação cedo, de não se dispor de um aparelho auditivo corretamente ajustado, de não existir pessoal adequadamente qualificado, de não se ter conseguido motivar os pais, para que insistissem no uso constante do aparelho auditivo [...] as condiçóes para o sucesso são objetivos ideais pelos quais alguns podem desejar lutar para alcançar, mas, ao mesmo tempo, essas condiçóes são uma desculpa pronta para o que os outros consideram "insucessos", na abordagem básica do tratamento da criança surda. (CARBIN; BOESE, 1999, p. 145).

Autores e pesquisadores da área da surdez, como Sacks (2010) e Dorziat (1997), avaliam que o Oralismo e a tentativa de eliminação de sinais tiveram como consequência a deterioração das conquistas educacionais das pessoas com deficiência auditiva e do grau de instrução alcançado pelas mesmas.

\section{b. Comunicação total}

Pode-se dizer que a grande conquista dessa concepção, a partir da década de 1970, foi priorizar a comunicaçáo dos surdos entre estes e as demais pessoas, que deveria acontecer não apenas através da língua oral. A pessoa com deficiência auditiva deixa de ser reconhecida pela visão patológica, e passa a ser vista como uma pessoa capaz (OLIVEIRA, 2002). 
Dorziat (1999) justifica o uso da Comunicação Total na educação devido ao fato de que a maioria dos professores de surdos é ouvinte e, portanto, há dificuldades (sejam de ordem orgânica, de conhecimento ou de habilidade) de tornar a comunicação eficiente entre ambas as partes. Um lado não consegue se apropriar plenamente do código do outro; por isso, de acordo com Denton (1976, apud FREEMAN, CARBIN \& BOESE, 1999), a Comunicação Total inclui todo o espectro dos modos linguísticos: gestos criados pelas crianças, língua de sinais, fala, leitura orofacial, alfabeto manual, leitura e escrita.

Para Dorziat (1997), o grande problema dessa metodologia é que:

Como não existem na língua de sinais certos componentes da estrutura frasal do português (preposição, conjunçáo etc.), são criados sinais para expressá-los. Além disso, utilizam-se marcadores de tempo, número e gênero para descrever a língua portuguesa através de sinais. A isto se chama de Português Sinalizado. Outra estratégia utilizada pela Comunicação Total é o uso de sinais na ordem do português sem, no entanto, utilizar marcadores, como no português sinalizado. $\mathrm{O}$ que existe em ambos os casos é um ajuste de sinais à estrutura da língua portuguesa. (DORZIAT, 1997, p. 16).

A conclusão que alguns autores obtêm a partir dessa concepção é que a Comunicação Total serviu mais aos pais e professores ouvintes que aos alunos com surdez (OLIVEIRA, 2002).

\section{c. Bilinguismo}

O Bilinguismo pressupóe que a criança deve ter acesso, o quanto antes, a duas línguas: a Libras e a língua portuguesa na modalidade escrita (considerando o contexto brasileiro). Para Ferreira Brito (1993, apud DORZIAT, 1999), o ensino nessa metodologia deve ser ministrado para os surdos da mesma forma como as línguas estrangeiras, isto é, primeiramente, são proporcionadas as experiências linguísticas na língua materna (no caso, a Libras) e, depois de sedimentada a linguagem nas crianças, ensina-se a língua majoritária do país como segunda língua.

Sacks (2010) confirma essa ideia, ao dizer que:

A língua de sinais deve ser introduzida e adquirida o mais cedo possível, senão seu desenvolvimento pode ser permanentemente retardado e prejudicado, com todos os problemas ligados à capacidade de "proposicionar" [...] no caso dos profundamente surdos, isso só pode ser feito por meio da língua de sinais. Portanto, a surdez deve ser diagnosticada o mais cedo possível. As crianças surdas precisam ser postas em contato primeiro com pessoas fluentes na língua de sinais, sejam seus pais, professores ou outros. Assim que a comunicação por sinais for aprendida, e ela pode ser fluente aos três anos de idade, tudo então pode decorrer: livre intercurso de pensamento, livre fluxo de informaçóes, aprendizado da leitura e escrita e, talvez, da fala. Não há indícios de que o uso de uma língua de sinais 
iniba a aquisição da fala. De fato, provavelmente, ocorre o inverso. (SACKS, 2010, p. 38).

Oliveira (2002) também expóe que, na instauração real do Bilinguismo, a língua de sinais deve ser considerada imprescindível, pois possibilita o domínio linguístico e a capacidade de expressão de modo pleno e seguro; e que a língua oral, ou escrita em português, servirá para que o surdo se comunique com o meio.

Apesar dos aspectos favoráveis à aprendizagem da língua de sinais, existem obstáculos para sua concretização, como a pouca habilidade manual e até a falta de conhecimento de como a própria comunidade de surdos se organiza, no contato fora da instituição entre professor e surdo (DORZIAT, 1999).

Além disso, conforme Quadros (2004), há experiências na educação bilíngue que ainda repetem um modelo de reparaçáo e tratamento da pessoa surda - como se esta pudesse ter a surdez eliminada. Nessas ocorrências, a língua de sinais é usada apenas como um recurso extra, sendo um meio para se ensinar o português, ao invés de ser respeitado o direito da pessoa surda de se comunicar através de sua língua, cuja natureza é visual-espacial. Assim, acaba havendo a sobreposição do português (língua da maioria) à língua de sinais.

Segundo Dorziat (2004), atualmente, a noção de inclusão relativa aos alunos surdos (principalmente não oralizados) recomenda que exista acessibilidade à comunicação, e que esta aconteça através da língua de sinais. Todavia, essa comunicação tem ficado restrita ao intérprete e ao surdo, sem levar em conta:

A interação com o professor e com os demais colegas, a importância das relaçóes humanas, dos processos de formação de identidade e do estabelecimento de conexáo entre os conteúdos escolares e as formas particulares (visuais) de apreensão e construção de conhecimentos. (DORZIAT, 2004, p. 03).

A mesma autora afirma, também, que é impossível tratar sobre inclusão sem considerar as possibilidades de desenvolvimento dos indivíduos e de sua participação como cidadãos. E, ponderando que os surdos são pessoas com diferentes formas de vida e representam diferentes papeis sociais, não se pode negar, ao falar de inclusão, esse aspecto imprescindível ao ser humano - a linguagem.

\section{Considerações finais}

Embora ao longo da história da educação dos surdos tenham existido diferentes propostas educacionais, podemos perceber que a aceitação e o reconhecimento da língua de sinais são imprescindíveis para alcançar a qualidade nesse âmbito. Mais que isso, a língua de sinais é indispensável para que a criança, profundamente surda, atinja um nível de desenvolvimento cognitivo suficiente para se constituir como sujeito, comunicar-se e significar o (dar sentido ao) seu mundo, em todas as suas extensôes de convivência - como a casa, a escola e a comunidade. 
Desses espaços, a escola é um dos mais fundamentais nesse processo de desenvolvimento e de inclusão da pessoa com deficiência. Portanto, é preciso que a comunicação usada ali seja fluente e constante, para, de fato, contemplar as necessidades linguísticas da pessoa surda. Afinal, se alguém com surdez - especialmente pré-linguística - não aprender a língua de sinais o quanto antes em sua vida (através da exposição constante à mesma), corre o risco de não se apropriar de uma língua materna e, por consequência, interromper seu desenvolvimento pessoal, social e também profissional.

Deve-se ter em mente, também, que a comunicação dentro da escola serve não só para ampliar os conhecimentos, mas também para estreitar as relaçôes com colegas, professores, intérpretes e outros funcionários. Somente assim, com a possibilidade de uma comunicação eficiente e real, é que a criança surda será capaz de pertencer - sentindo-se pertencente ao espaço e que este também o pertence -, podendo interferir nesse espaço, transformando-o. Desta forma, acontecerá a inclusão, que vai além de permitir que uma pessoa acesse, faça parte de determinado lugar, simplesmente por estar lá. Faz parte da inclusão promover condiçóes para que uma pessoa interaja com outra, modifique o espaço e faça algo de diferente no mesmo, podendo deixar de ser "só mais um" ali.

Quanto às dificuldades para a aprendizagem da língua de sinais, elas existem e devem, sim, ser assumidas. Porém, não justificam qualquer acomodação, de todas as pessoas envolvidas no assunto - principalmente educadores -, à situação atual. São necessárias novas iniciativas de ordem pedagógica e social, baseadas na aceitação e adaptação às peculiaridades do ser humano. Para isso, demanda-se um processo de construção de novo entendimento político e ideológico de escola, suscitando maneiras de enfrentar o fracasso com maior eficácia.

Para que uma inclusão real aconteça, a escola, como espaço de construção de conhecimento e de laços afetivos, precisa observar a interação do surdo através da língua de sinais, valorizar conteúdos escolares e torná-los significativos, buscando relacionar esses conteúdos com a cultura surda. E, aos poucos, incentivar ouvintes para que também aprendam a língua de sinais desde cedo. Desse modo, os surdos serão capazes de retirar-se da situação de desvantagem, podendo se comunicar não somente na escola ou entre si, mas também de se comunicar, participar e pertencer à sociedade toda em que estáo inseridos.

\section{Referências}

AMARAL, L. A. Pensar a diferença/deficiência. Brasília: CORDE, 1994.

AMARAL, A. L. Pertencimento. Disponível em: <http://escola.mpu.mp.br/dicionario/tiki-index.php?page=Pertencimento $>$. Acesso em: 31 mar. 2014. 2006 .

BRASIL. Decreto 5626, de 22 de dezembro de 2005. Regulamenta a Lei no 10.436/2002, que dispóe sobre a Língua Brasileira de Sinais - Libras, e o art. 18 da Lei no 10.098/2000. Publicado no Diário Oficial da Uniáo em 23 de dezembro de 2005.

Lei 9394, de 20 de dezembro de 1996. Estabelece as diretrizes e bases da educaçáo nacional. Publicada no Diário Oficial da União em 23 de dezembro de 1996. 
BRASIL. Lei 10.436, de 24 de abril de 2002. Dispóe sobre a Libras e dá outras providências. Publicada no Diário Oficial da União em 24 de abril de 2002.

BUENO, J. G. S. Função social da escola e organização do trabalho pedagógico. Educar, Curitiba, n. 17, p. 101-110. Editora da UFPR. 2001.

CAPOVILLA, F.; RAPHAEL, W. D. Dicionário enciclopédico ilustrado trilíngue da língua de sinais brasileira. São Paulo: Edusp, 2001.

DORZIAT, A. Bilinguismo e surdez: para além de uma visão linguística e metodológica. In: SKLIAR, C. (Org.). Atualidades da educaçáo bilíngue para surdos: processos e projetos pedagógicos. 2ed. Porto alegre: Mediação, 1999. v. 1. p. 27-40.

.Educação de surdos no ensino regular: inclusão ou segregação? In: Revista do Centro de Educação, n. 24. Santa Maria, 2004.

Metodologias específicas ao ensino de surdos: análise crítica. Revista Integração, Brasília, v. 1, n. 18, p. 13-18, 1997.

FREEMAN, R. D.; CARBIN, C. F. \& BOESE, R. J. 1999. Seu filho náo escuta? Um guia para todos que lidam com crianças surdas. Brasília: Coordenadoria Nacional para Integraçáo da Pessoa Portadora de Deficiência - CORDE.

GOLDFELD, M. A criança surda. Linguagem e cognição numa perspectiva sócio-interacionista. São Paulo: Plexus, 2002.

IBGE. Censo 2010: Pessoas com deficiência. Disponível em: <http://www.ibge.gov.br>. Acesso em: 30 mar. 2014 .

MARTINS, L P. Artigo 2 - Definiçóes. A convenção sobre os direitos das pessoas com deficiência comentada. Coordenação de Ana Paula Crosara de Resende e Flávia Maria de Paiva Vital. Brasília: Secretaria Especial dos Direitos Humanos. Brasília: 2008. p. 28-30.

MELLO, A. G. Surdos oralizados e não oralizados: uma visão crítica. In: Segundo Congresso Virtual “Integración sin Barreras em el Siglo XXI”. 2001.

OLIVEIRA, L. A. A escrita do surdo: relação texto e concepção. Juiz de Fora: UFJF, 2002.

QUADROS, R. M. de. Educaçáo de surdos: efeitos de modalidade e práticas pedagógicas. 2004. Disponível em: <http://www.porsinal.pt/index.php?ps=artigos\&idt=artc\&cat=7\&idart=50>. Acesso em: 28 mar. 2014.

REILY, L. Escola inclusiva: Linguagem e mediação. 3. ed. Campinas: Papirus, 2008.

RIBEIRO, S. L. Espaço escolar: um elemento (in)visível no currículo. Sitientibus, Feira de Santana, n. 31, p. 103-118, jul./dez. 2004.

RODRIGUES, Z. F. F. Histórico da educaçáo dos surdos. 2008. Disponível em: <http://www.feneis.org.br/ page/noticias_detalhe.asp?categ=1\&cod=621>. Acesso em: 20 mar. 2014.

SACKS, O. Vendo Vozes: Uma viagem ao mundo dos surdos. São Paulo: Companhia de Bolso, 2010. Edição original publicada em 1989.

SÃO PAULO. Decreto n. 52.785/2011, de 10 de novembro de 2011. Cria as Escolas Municipais de Educação Bilíngue para Surdos - EMEBS, na Rede Municipal de ensino. Publicado na Secretaria do Governo Municipal, em 10 de novembro de 2011.

SASSAKI, R. K. Artigo 24 - Educação. In: A convenção sobre os direitos das pessoas com deficiência comentada. Coordenação de Ana Paula Crosara de Resende e Flávia Maria de Paiva Vital. Brasília: Secretaria Especial dos Direitos Humanos. CORDE, 2008, p. 83.

. Nomenclatura na área da surdez. Disponível em: <http://www.prefeitura.sp.gov.br/cidade/secr'arias/ upload/saude/arquivos/deficiencia/Nomenclatura_na_area_da_surdez.pdf>. Acesso em: 24 mar. 2014.

. Nomenclatura na área da surdez. 2002, p. 1-4. Disponível em: <http://www.prefeitura.sp.gov.br/cidade/ secretarias/upload/saude/arquivos/deficiencia/Nomenclatura_na_area_da_surdez.pdf>. Acesso em maio 2014.

SMITH, D. D. Introdução à educação especial: ensinar em tempos de inclusão. Tradução Sandra Moreira de Carvalho. 5. ed. Porto Alegre: Artmed, 2008.

VYGOTSKY, L S. Pensamento e inguagem. São Paulo: Martins Fontes, 1991. 
A importância da língua de sinais para o desenvolvimento da pessoa surda: a noção de inclusão associada ao sentimento de pertencimento no espaço escolar

\section{Nota}

${ }^{1}$ Cabe aqui ressaltar que, para a Lei 10.436/2002 e o Decreto Federal 5626/2005, o significado da sigla Libras é Língua Brasileira de Sinais; no entanto, os autores Capovilla \& Raphael (2001) e Sassaki (2005) argumentam que o significado adequado de Libras é Língua de Sinais Brasileira, conforme discutido no tópico "Libras - Língua de Sinais Brasileira".

\section{Correspondência}

Patricia Velho Dall'Astra - Rua Lauro Linhares, 1520 ap. 606. Trindade, CEP: 88036-002, Florianópolis, Santa Catarina - Brasil.

E-mail: patricia.dallastra@gmail.com

Recebido em 23 de abril de 2014

Aprovado em 07 de junho de 2014 
